\title{
Programmed necrosis, not apoptosis, is a key mediator of cell loss and DAMP-mediated inflammation in dsRNA-induced retinal degeneration
}

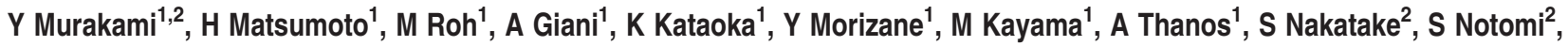

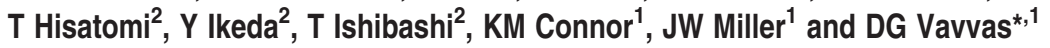

There is no known treatment for the dry form of an age-related macular degeneration (AMD). Cell death and inflammation are important biological processes thought to have central role in AMD. Here we show that receptor-interacting protein (RIP) kinase mediates necrosis and enhances inflammation in a mouse model of retinal degeneration induced by dsRNA, a component of drusen in AMD. In contrast to photoreceptor-induced apoptosis, subretinal injection of the dsRNA analog poly(l: C) caused necrosis of the retinal pigment epithelium (RPE), as well as macrophage infiltration into the outer retinas. In Rip3 ${ }^{-1-}$ mice, both necrosis and inflammation were prevented, providing substantial protection against poly(I: C)-induced retinal degeneration. Moreover, after poly(I: C) injection, Rip3 ${ }^{-1-}$ mice displayed decreased levels of pro-inflammatory cytokines (such as TNF- $\alpha$ and IL-6) in the retina, and attenuated intravitreal release of high-mobility group box-1 (HMGB1), a major damage-associated molecular pattern (DAMP). In vitro, poly(l:C)-induced necrosis were inhibited in Rip3-deficient RPE cells, which in turn suppressed HMGB1 release and dampened TNF- $\alpha$ and IL- 6 induction evoked by necrotic supernatants. On the other hand, Rip3 deficiency did not modulate directly TNF- $\alpha$ and IL- 6 production after poly(l:C) stimulation in RPE cells or macrophages. Therefore, programmed necrosis is crucial in dsRNA-induced retinal degeneration and may promote inflammation by regulating the release of intracellular DAMPs, suggesting novel therapeutic targets for diseases such as AMD.

Cell Death and Differentiation (2014) 21, 270-277; doi:10.1038/cdd.2013.109; published online 16 August 2013

Chronic inflammation underlies various neural and retinal degenerative diseases such as age-related macular degeneration (AMD), the leading cause of blindness in industrialized countries. ${ }^{1}$ AMD is a slowly progressive disease characterized by extracellular deposits formed beneath the retinal pigment epithelium (RPE) (called drusen), degeneration of the RPE and photoreceptors, the subsequent development of geographic atrophy and/or choroidal neovascularization, along with the accumulation of inflammatory cells in the macula. $^{2,3}$ Drusen contains several pro-inflammatory components such as complement proteins, lipoproteins, oxidized lipids and double-stranded RNA (dsRNA). ${ }^{4,5}$ Moreover, identification of genetic variations in inflammation-related genes, such as complement genes, implicates inflammation as a potential factor in AMD. ${ }^{6}$ However, the key factors that promote inflammation in AMD and the intimate relationship between retinal inflammation and cell death remain elusive.

Inflammation is an important pathological feature of necrosis. ${ }^{7}$ Damage-associated molecular patterns (DAMPs) released from necrotic cells enhance the inflammatory response and tissue injury. ${ }^{8,9}$ Although necrosis was thought to be an uncontrolled process of cell death, it is now known to proceed through regulated components in certain instances. ${ }^{10}$ Receptor-interacting protein 3 (RIP3) is a key mediator of programmed necrosis induced through death receptors or toll-like receptors (TLRs). ${ }^{11}$ During necrosis induction, RIP3 interacts with RIP1 to form a pro-necrotic complex, which is stabilized by phosphorylation of their serine/ threonine kinase domains. ${ }^{12-14}$ This pathway is critically important in development and in many pathological processes. ${ }^{15-17}$ Notably, Rip3 deficiency not only prevents necrosis but also ameliorates inflammation in models of colitis, sepsis, retinal detachment and inherited retinal degeneration. ${ }^{18-21}$ However, the mechanisms by which RIP3 regulates inflammation have not been fully explored.

The dsRNA component of drusen is a ligand for TLR3 that mediates innate immune response and cell death. Whereas RIP1 acts as a multifunctional adaptor protein that regulates $\mathrm{NF}-\kappa \mathrm{B}$-dependent inflammation, apoptosis and necrosis in TLR3 signaling, RIP3 has a more specific role, which induces necrosis through the formation of the pro-necrotic complex. ${ }^{22,23}$ Although previous studies have shown that intraocular injection of polyinosinic-polycytidylic acid (poly $(\mathrm{I}: \mathrm{C})$ ), a synthetic analog of dsRNA, induces TLR3-dependent retinal

\footnotetext{
${ }_{1}^{1}$ Department of Ophthalmology, Retina Service, Angiogenesis Laboratory, Massachusetts Eye and Ear Infirmary, Harvard Medical School, Boston, MA, USA and ${ }^{2}$ Department of Ophthalmology, Graduate School of Medical Sciences, Kyushu University, Fukuoka, Japan

*Corresponding author: DG Vavvas, Department of Ophthalmology, Retina Service, Angiogenesis Laboratory, Massachusetts Eye and Ear Infirmary, Harvard Medical School, 243 Charles Street, Boston, MA 02114, USA. Tel: +617 573 6874; Fax: + 617573 3011; E-mail: vavvas@meei.harvard.edu

Keywords: retina; neuroprotection; necrosis; macula; degeneration

Abbreviations: AMD, age-related macular degeneration; DAMPs, damage-associated molecular patterns; GCL, ganglion cell layer; HMGB1, high-mobility group box 1; INL, inner nuclear layer; LPS, lipopolysaccharide; Nec-1, necrostatin-1; ONL, outer nuclear layer; RIP, receptor-interacting protein; RPE, retinal pigment epithelium; TLRs, toll-like receptors; TEM, transmission electron microscopy; WT, wild type; ZO-1, zona occludens 1

Received 23.1.13; revised 15.6.13; accepted 25.6.13; Edited by N Bazan; published online 16.8.2013
} 
degeneration, ${ }^{24,25}$ the downstream molecular and biological events were not elucidated. In this study, we examined the mechanism of cell death of RPE and photoreceptors in dsRNA-induced retinal degeneration and identified programmed necrosis to promote inflammation by regulating the release of intracellular DAMPs and to be crucial in dsRNA-induced retinal degeneration. These findings suggest that the RIP kinase-dependent necrotic pathway is a potential target to prevent retinal inflammation and degeneration associated with dsRNA accumulation.

\section{Result}

RIP3-mediated necrosis, rather than apoptosis, is the major mediator of dsRNA-induced retinal degeneration in mice. To analyze the types of cell death involved in dsRNA-induced retinal degeneration, we investigated the morphology of the RPE and photoreceptors by transmission electron microscopy (TEM). Two days after poly(I:C) injection, the dying RPE cells exhibited necrotic morphology accompanied by swollen cytoplasmic vacuoles in wild-type (WT) mice (Figure 1a). No apoptotic RPE cells with cellular shrinkage or nuclear condensation were observed. On the other hand, the outer nuclear layer (ONL) of photoreceptors exhibited the presence of both apoptotic and necrotic nuclei after poly(l:C) injection (Figure 1b). The occurrence of photoreceptor necrosis was further supported by the finding of swollen vacuoles and disrupted mitochondria in the inner segments (Figure 1c). In contrast, features of necrosis in RPE and photoreceptors after poly(I:C) injection were markedly notably absent in Rip3-deficient animals (Figures 1d-f).
To further examine the role of necrosis in dsRNA-induced retinal degeneration, we examined the expression levels of RIP3, which is markedly upregulated during the induction of necrosis in pancreatitis, enteritis and retinal degeneration. ${ }^{13,20,21,26}$ Subretinal injection of PBS did not affect the expression levels of RIP3 compared with untreated retinas in WT mice (Supplementary Figure S1). In contrast, subretinal injection of poly $(\mathrm{I}: \mathrm{C})$ increased retinal RIP3 expression over five-fold at both mRNA and protein levels $(P<0.05$, Figures $2 \mathrm{a}$ and $\mathrm{b})$.

We next evaluated the effect of Rip3 deficiency on poly(I:C)-induced retinal degeneration. TUNEL staining, which labels DNA breaks in both necrotic and apoptotic cells, showed that poly $(\mathrm{I}: \mathrm{C})$ treatment induced a substantial increase in TUNEL-positive cells mainly in the ONL of the WT mouse retinas 2 days after injection (Figures $2 c$ and d). This increase in TUNEL-positive cells was significantly reduced in Rip3-deficient animals $(P<0.05$, Figures $2 \mathrm{c}$ and d).

We also assessed the involvement of the caspasedependent apoptotic pathway in poly $(\mathrm{I}: \mathrm{C})$-induced retinal degeneration. Cleavage of caspase-3, a key effector caspase, was observed 2 days after poly(I:C) injection; however, the frequency of cleaved caspase-3-positive cells was much lower than that of TUNEL-positive cells (Supplementary Figure S2). Treatment with the pan-caspase inhibitor Z-VAD at the time of poly (I:C) injection suppressed caspase-3 cleavage in WT mouse retinas (Supplementary Figure S2, $P<0.05)$ but did not sufficiently reduce TUNEL positivity in WT mice (Figures $2 \mathrm{c}$ and d). Z-VAD treatment did not provide any additional significant protective effect in Rip3 $^{-1-}$ mice (Figures $2 \mathrm{c}$ and d). Histological analysis demonstrated severe degeneration of the RPE and

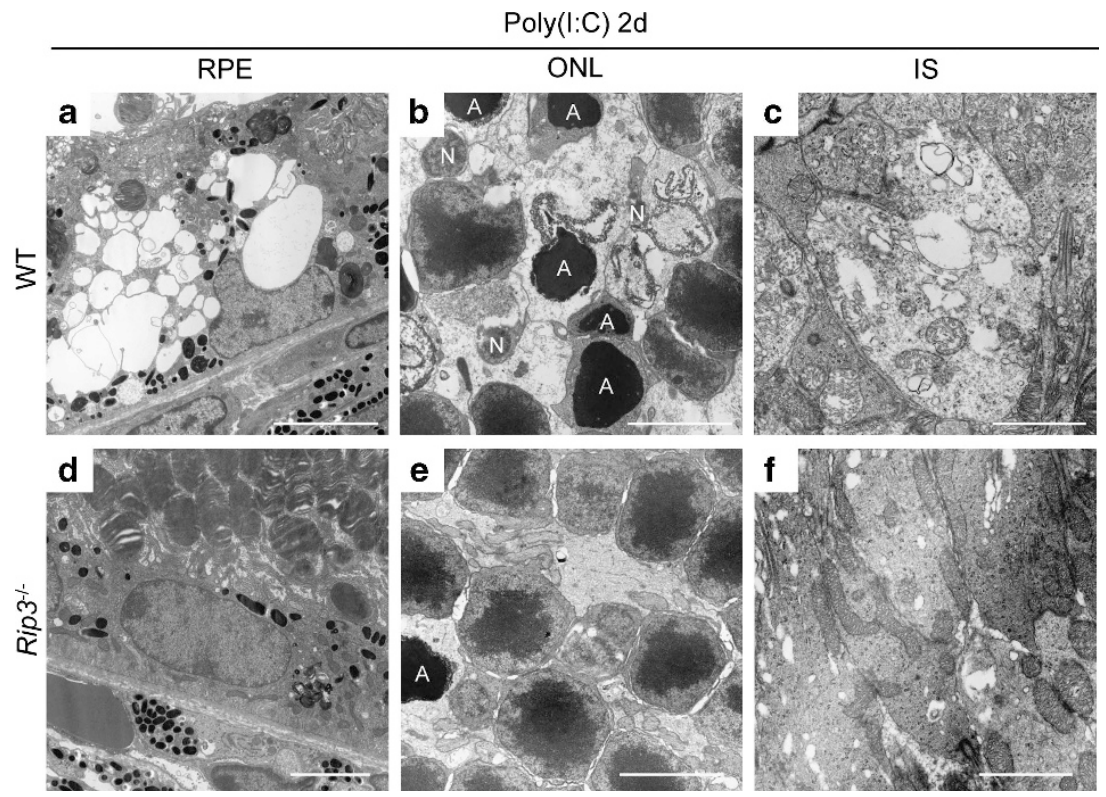

Figure 1 RIP3 mediates necrosis of the RPE and photoreceptors after dsRNA injection in mice. (a-f) TEM photomicrographs in the RPE (a, d) and the ONL (b and $\mathbf{e})$ and IS (c and $\mathbf{f})$ of photoreceptors in the WT (a-c) or Rip3 ${ }^{-1-}(\mathbf{d}-\mathbf{f})$ retinas 2 days after subretinal poly $(\mathrm{I}: \mathrm{C})$ injection. Necrotic cell death of photoreceptors and RPE cells induced by poly(I:C) was substantially prevented in Rip3 ${ }^{-1-}$ mice. A: apoptotic cell, N: necrotic cell. Scale bar, $5 \mu \mathrm{m}(\mathbf{a}, \mathbf{b}, \mathbf{d}$ and $\mathbf{e}), 2 \mu \mathrm{m}$ (c and f) 

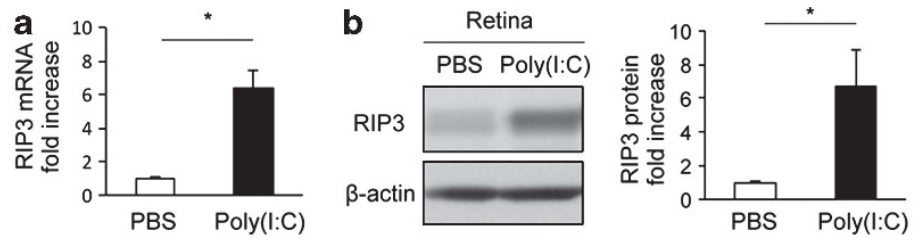

c

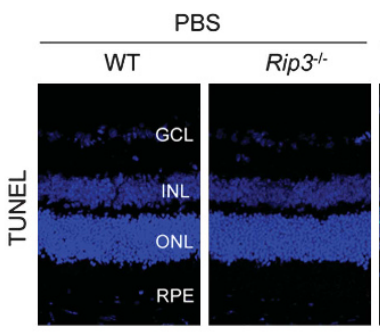

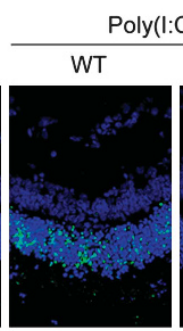
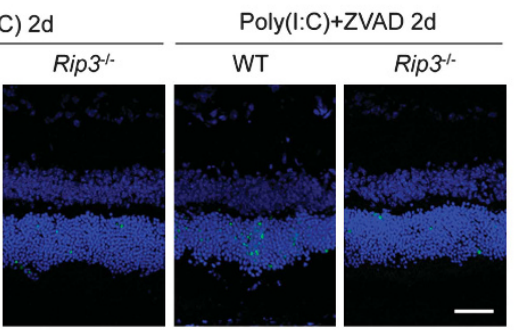

d

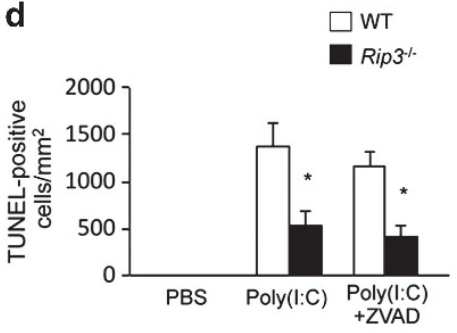

e
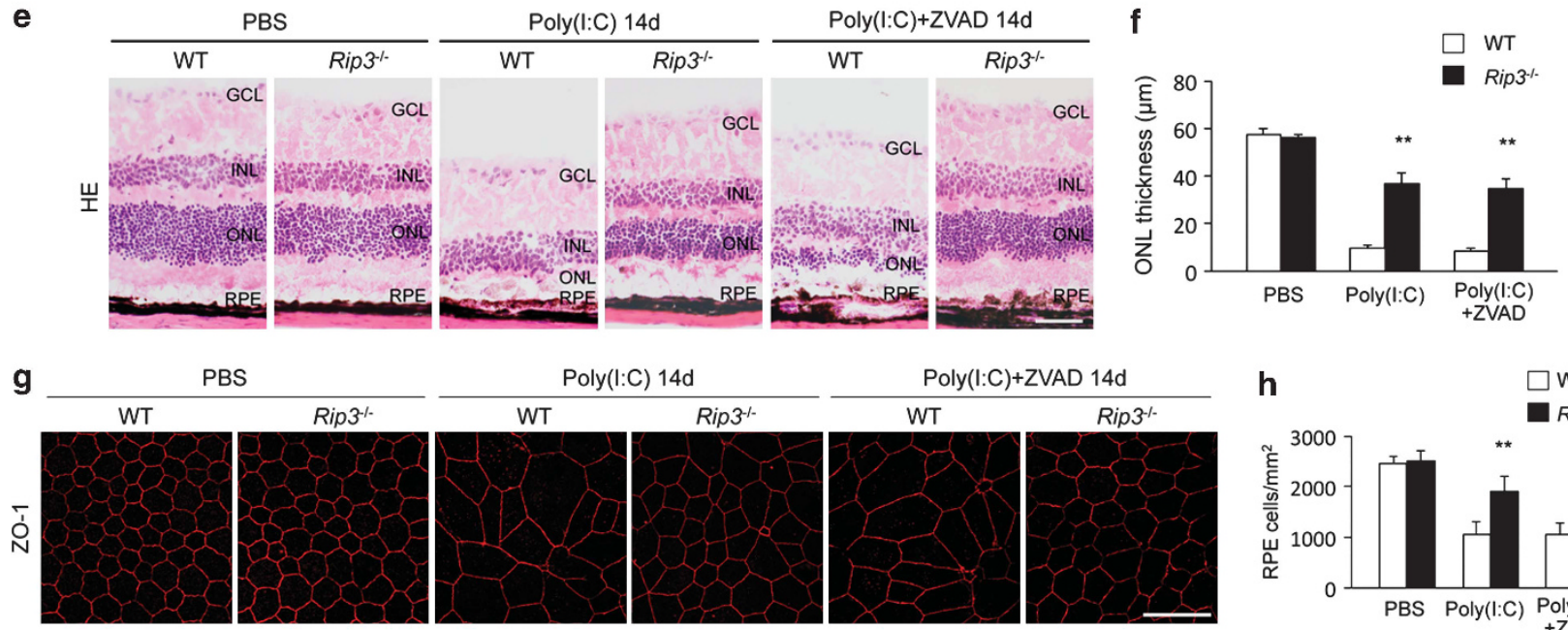

PBS
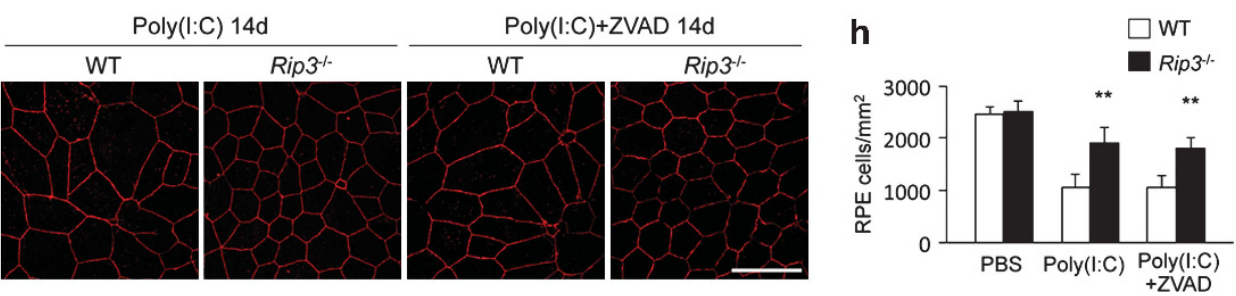

Figure 2 RIP3 mediates photoreceptor and RPE cell loss induced by dsRNA in mice. (a) Quantitative real-time PCR analysis for RIP3 in the retina 2 days after subretinal injection of PBS or poly $(\mathrm{I}: \mathrm{C})\left(n=4\right.$ each). ${ }^{*} P<0.05$. (b) Western blot analysis for RIP3 in the retina 2 days after subretinal injection of PBS or poly(I: C) ( $n=4$ each). Levels normalized to $\beta$-actin. The bar graphs indicate the relative level of RIP3 to $\beta$-actin by densitometric analysis. ${ }^{*} P<0.05$. (c and $\mathbf{d}$ ) TUNEL (green) and DAPI (blue) staining (c) and quantification of TUNEL-positive cells (d) in WT or Rip3 ${ }^{-1}$ - retinas 2 days after subretinal injection of PBS ( $n=6$ each), poly $(\mathrm{l}: \mathrm{C})(n=6$ in WT and $n=7$ in Rip3 $\left.{ }^{-1-}\right)$, or poly $(I: C)$ plus Z-VAD $(n=7$ each). Subretinal poly(l:C) injection induced TUNEL-positive cells mainly in the ONL in WT mice. This increase in TUNEL-positive cells was reduced by Rip3 deficiency, but not by the pan-caspase inhibitor Z-VAD. GCL: ganglion cell layer, INL: inner nuclear layer. Scale bar, $50 \mu \mathrm{m} .{ }^{*} P<0.05$ versus WT eyes treated with poly(l:C). (e and f) Retinal histology (e) and quantification of ONL thickness (f) in the WT or Rip3 ${ }^{-I-}$ retinas 14 days after subretinal injection of PBS ( $n=5$ each), poly(l : C) ( $n=5$ each) or poly(I: C) plus Z-VAD ( $n=7$ in WT and $n=6$ in Rip3 ${ }^{-l-}$ ). Rip3 deficiency prevented the degeneration of photoreceptors and RPE after poly $(\mathrm{l}: \mathrm{C})$ injection. Scale bar, $50 \mu \mathrm{m}$. ${ }^{*} P<0.01$ versus WT eyes treated with poly $(\mathrm{I}: \mathrm{C})$. (g and $\left.\mathbf{h}\right) \mathrm{ZO}-1$ staining $(\mathbf{g})$ and quantification of ZO-1-positive RPE cells $(\mathrm{h})$ in the WT or Rip3 ${ }^{-I}$ choroidal flatmounts 14 days after subretinal injection of PBS $(n=4$ each), poly(l:C) $(n=6$ each) or poly(l:C) plus Z-VAD ( $n=6$ each). The loss of RPE cells after poly(I : C) injection was attenuated in Rip3 ${ }^{-1-}$ mice. Scale bar, $50 \mu \mathrm{m} .{ }^{* \star} P<0.01$ versus WT eyes treated with poly(I : C). $(\mathbf{a}, \mathbf{b}, \mathbf{d}, \mathbf{f}$ and $\mathbf{h})$ The graphs show mean \pm S.E.M.

photoreceptors 14 days after poly(I: C) injection in WT mice (Figures $2 \mathrm{e}$ and $\mathrm{f}$ ). In contrast, there was relative preservation of the structure of the RPE and photoreceptors in Rip3 ${ }^{-1-}$ mice $(P<0.01$, Figures $2 \mathrm{e}$ and $\mathrm{f})$. Immunostaining for zona occludens 1 (ZO-1) confirmed that the loss of RPE cells after poly $(\mathrm{I}: \mathrm{C})$ injection was attenuated in $\mathrm{Rip}^{-/-}$mice $(P<0.01$, Figures $2 \mathrm{~g}$ and $\mathrm{h})$. Z-VAD treatment, however, did not affect the loss of the photoreceptors or RPE induced by poly $(\mathrm{I}: \mathrm{C})$ in WT (Figures $2 \mathrm{e}$ and f) or Rip3 ${ }^{-/-}$(Figures $2 \mathrm{~g}$ and $\mathrm{h}$ ) mice. Consistent with the data from genetic Rip3 ablation, treatment with the RIP1 kinase inhibitor necrostatin-1 (Nec-1) ameliorated poly $(\mathrm{I}: \mathrm{C})$-induced retinal degeneration in WT mice $(P<0.05$, Supplementary Figure S3).
Collectively, these data indicate that RIP3-dependent necrosis has a critical role in dsRNA-induced retinal degeneration.

RIP3 promotes a retinal inflammatory response after dsRNA injection in mice. We next assessed the effect of subretinal poly $(\mathrm{I}: \mathrm{C})$ injection on the inflammatory response in Rip3 ${ }^{-1-}$ mice. Immunostaining for CD11b demonstrated a robust macrophage infiltration around the RPE and in the subretinal space 2 days after poly(I:C) injection in WT mice (Figures $3 a$ and b). In contrast, the macrophage infiltration was significantly reduced in $\mathrm{Rip}^{-1-}$ mice $(P<0.01$, Figures $3 \mathrm{a}$ and $\mathrm{b})$. Correspondingly, treatment 
a

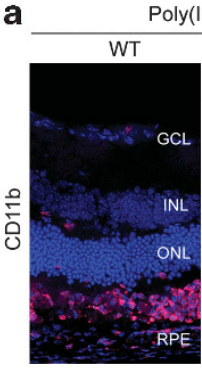

oly(l:C) $2 d$

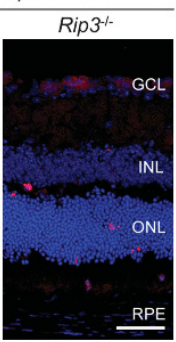

b
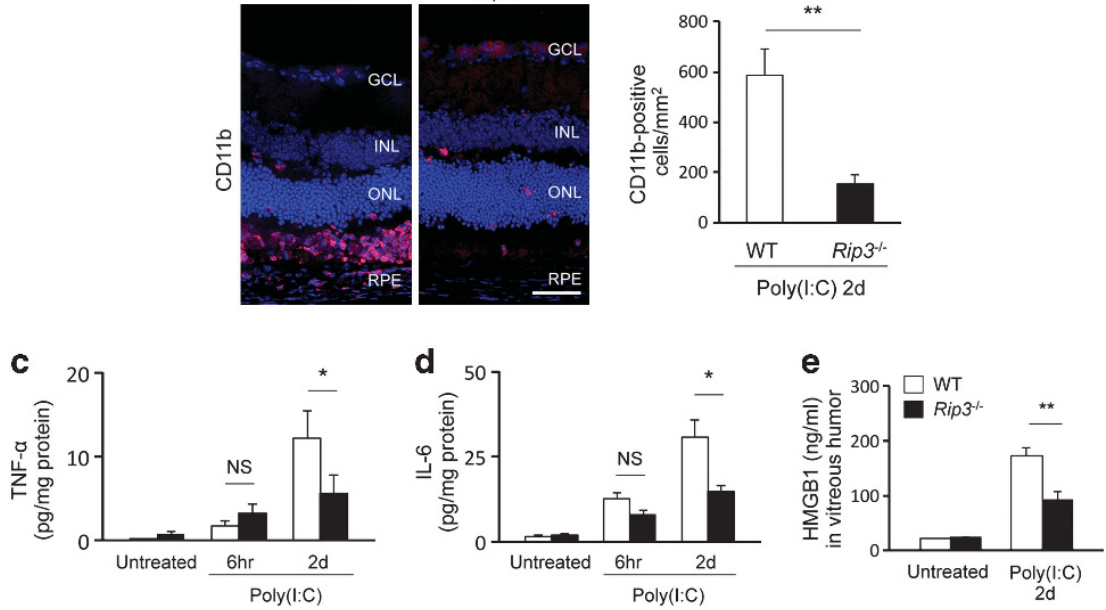

Figure 3 RIP3 promotes retinal inflammatory response in dsRNA-induced retinal degeneration in mice. (a and b) Immunofluorescence for CD11b (a) and quantification of CD11b-positive cells (b) in WT or Rip3 ${ }^{-1-}$ retinas 2 days after subretinal poly(I:C) injection ( $n=8$ each). Infiltration of CD11b-positive cells into the outer retina was substantially decreased in Rip3 ${ }^{-1-}$ mice. Scale bar, $50 \mu \mathrm{m} .{ }^{* *} P<0.01$. (c and d) ELISA to detect TNF- $\alpha$ (c) and IL-6 (d) in the WT or Rip $^{-1-}$ retinas before $\left(n=4\right.$ each) and $6 \mathrm{~h}\left(n=5\right.$ each) and 2 days $\left(n=8\right.$ in WT and $n=7$ in Rip3 $\left.{ }^{-1-}\right)$ after poly(I:C) injection. TNF- $\alpha$ and IL- 6 generation 2 days after injection was suppressed in Rip3 ${ }^{-1}-$ mice. ${ }^{*} P<0.05$. (e) ELISA for HMGB1 in the vitreous humor of WT or Rip3 ${ }^{-1-}$ mice before $(n=4$ each) and 2 days $\left(n=7\right.$ in WT and $n=8$ in Rip3 $\left.{ }^{-I-}\right)$ after poly $(I: C)$ injection. Intravitreal release of HMGB1 was decreased in Rip3 ${ }^{-I-}$ mice. ${ }^{* *} P<0.01$. (b-e) The graphs show mean + S.E.M.

with $\mathrm{Nec}-1$ also suppressed macrophage infiltration after poly(I:C) injection $(P<0.05$, Supplementary Figure S4). In contrast, Z-VAD treatment did not affect the recruitment of inflammatory cells induced by poly $(\mathrm{I}: \mathrm{C})$ (Supplementary Figure S4). We also examined the inner retinal inflammation by whole-mount staining for the microglial marker Iba-1. In WT mice, the number of microglial cells around the ganglion cell layer (GCL) was substantially increased 2 days after poly $(\mathrm{I}: \mathrm{C})$ injection (Supplementary Figure S5). In contrast, the microglial activation after poly $(\mathrm{I}: \mathrm{C})$ treatment was relatively decreased in $R i p 3^{-1}$ mice $(P<0.01$, Supplementary Figure S5).

We next evaluated the expression levels of pro-inflammatory cytokines in mouse retinas after poly $(\mathrm{I}: \mathrm{C})$ injection. The protein levels of TNF- $\alpha$ and IL- 6 were elevated at $6 \mathrm{~h}$ and further increased at $48 \mathrm{~h}$ after poly $(\mathrm{I}: \mathrm{C})$ injection in WT mice (Figures $3 c$ and d). Whereas the early induction of TNF- $\alpha$ and IL- 6 at $6 \mathrm{~h}$ did not differ between Rip $3^{-1}$ and WT mice, their levels at $48 \mathrm{~h}$ were substantially decreased in Rip3 ${ }^{-1-}$ mice $(P<0.05$, Figures $3 \mathrm{c}$ and $\mathrm{d})$.

Dying or damaged cells release DAMPs that activate immune responses via interaction with cellular receptors such as TLRs. ${ }^{7}$ As high-mobility group box 1 (HMGB1) is a major DAMP released from necrotic cells, ${ }^{27}$ we examined the changes in HMGB1 release after poly(I:C) treatment. Subretinal injection of poly $(\mathrm{I}: \mathrm{C})$ induced HMGB1 release into the vitreous humor of WT mice at $48 \mathrm{~h}$ after poly $(\mathrm{I}: \mathrm{C})$ injection. In contrast, this poly $(\mathrm{I}: \mathrm{C})$-induced $\mathrm{HMGB} 1$ release was significantly impaired in Rip3 ${ }^{-1-}$ mice compared with WT mice $(P<0.01$, Figure $3 e)$. These findings suggest that RIP3 may regulate the inflammatory responses in dsRNA-induced retinal degeneration and dampen the release of intracellular DAMPs.
RIP3-dependent necrosis releases DAMP and the necrotic supernatants enhance cytokine production from macrophages. We next examined the function of RIP3 in necrosis induction and cytokine production using primary RPE cells and macrophages derived from WT or Rip3 ${ }^{-1-}$ mice. A previous study showed that poly $(\mathrm{I}: \mathrm{C})$ combined with a pan-caspase inhibitor causes massive programmed necrosis in macrophages. ${ }^{28}$ Consistent with this, RPE cells treated with poly $(\mathrm{I}: \mathrm{C})$ and Z-VAD showed substantial reduction in cellular viability, which was completely reversed in Rip3 ${ }^{-1-}$ RPE cells (Figure 4a). In addition, treatment with poly $(\mathrm{I}: \mathrm{C})$ and Z-VAD induced a substantial release of HMGB1 from WT RPE cells into the supernatant (Figure 4b). In contrast, this HMGB1 release induced by poly (I:C) and Z-VAD was completely prevented in Rip3 ${ }^{-1-}$ RPE cells (Figure $4 b)$.

To further analyze the ability of DAMPs to promote inflammation, we incubated macrophages with the supernatant from normal or necrotic RPE cells. Whereas the addition of supernatants from RPE cells treated with poly(I:C) alone did not increase TNF- $\alpha$ and IL- 6 production levels in macrophages compared with those from control RPE cells, the supernatant from necrotic RPE cells treated with poly $(\mathrm{I}: \mathrm{C})$ and Z-VAD substantially increased TNF- $\alpha$ and IL- 6 production levels (Figures $4 c$ and $d$ ). In contrast, the supernatants from Rip3-deficient RPE cells with either treatment did not enhance cytokine production (Figures $4 \mathrm{c}$ and $\mathrm{d}$ ), suggesting that DAMPs released from necrotic cells are important for the amplification of the inflammatory response.

We next investigated whether RIP3 directly modulates $\mathrm{NF}-\kappa \mathrm{B}$ signaling and cytokine production in primary RPE cells and macrophages. Newton et al. ${ }^{29}$ previously reported that Rip3-deficient cells show normal NF- $\kappa \mathrm{B}$ signaling in response 


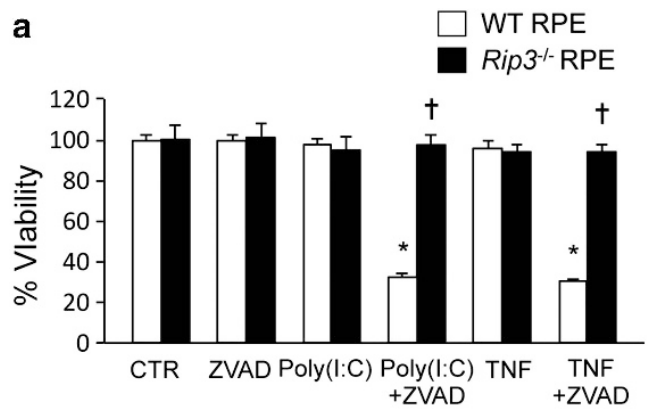

b
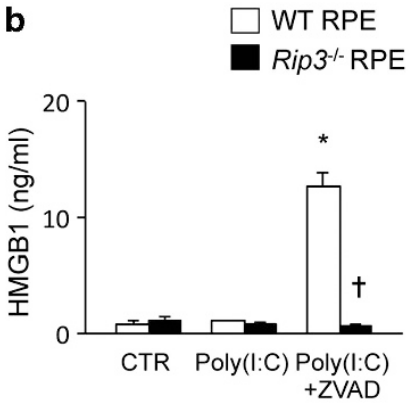

c

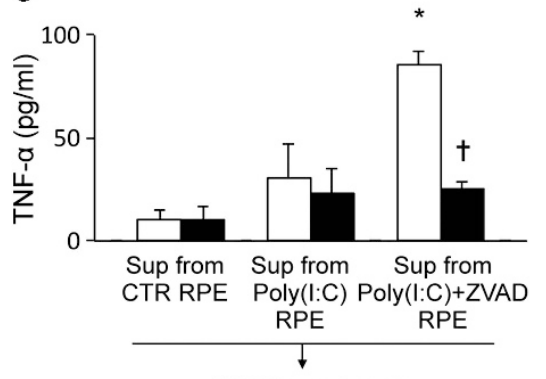

WT Macrophages

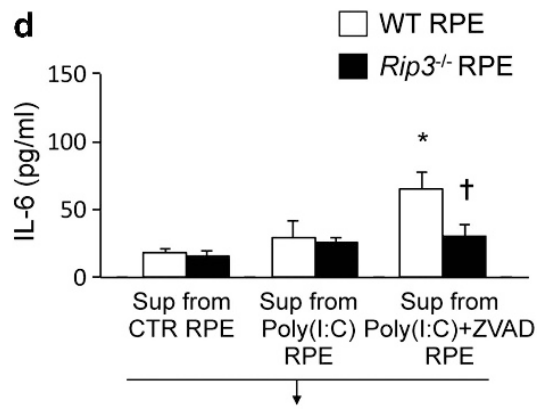

WT Macrophages

Figure 4 RIP3-dependent necrosis releases HMGB1, and the necrotic supernatants enhance cytokine production from macrophages. (a) Cell-viability assay in RPE cells $24 \mathrm{~h}$ after treatment with vehicle, Z-VAD $(30 \mu \mathrm{M})$, poly $(\mathrm{I}: \mathrm{C})(5 \mu \mathrm{g} / \mathrm{ml})$, poly $(\mathrm{I}: \mathrm{C})$ plus Z-VAD, TNF- $\alpha$ ( $30 \mathrm{ng} / \mathrm{ml})$ or TNF- $\alpha$ plus Z-VAD $(n=4$ each). The reduction in cellular viability by poly(I: C) plus Z-VAD or TNF- $\alpha$ plus Z-VAD was inhibited in Rip3-deficient cells. ${ }^{*} P<0.01$ versus controls. ${ }^{\dagger} P<0.01$ versus WT cells. (b) ELISA for HMGB1 in the supernatant of RPE cells $24 \mathrm{~h}$ after treatment with vehicle, poly(I:C) or poly $(\mathrm{l}: \mathrm{C})$ plus Z-VAD $(n=4$ each). HMGB1 release by poly $(I: C)$ plus Z-VAD was prevented in Rip3-deficient cells. ${ }^{*} P<0.01$ versus controls. ${ }^{\dagger} P<0.01$ versus WT cells. (c and d) ELISA for TNF- $\alpha$ (c) and IL-6 (d) in macrophages treated with necrotic supernatants. WT or Rip3 $^{-1-}$ RPE cells were treated with vehicle, poly $(I: C)$ or poly $(I: C)$ plus Z-VAD, and $3 \mathrm{~h}$ after stimulation, the culture medium was washed and replaced by fresh medium. After 24-h incubation, the cellular supernatant from RPE cells was applied to macrophages ( $n=4$ each). The supernatant from necrotic WT RPE cells treated with poly(I:C) plus Z-VAD increased TNF- $\alpha$ and IL-6 generation from macrophages. In contrast, in Rip3-deficient cells, TNF- $\alpha$ and IL-6 did not increase. ${ }^{*} P<0.01$ versus controls. ${ }^{\dagger} P<0.01$ versus WT cells. (a-d) The graphs show mean \pm S.D.

to TNF- $\alpha$ or lipopolysaccharide (LPS). Consistent with this report, RPE cells and macrophages derived from either WT or Rip3 $^{-1-}$ mice exhibited comparable time-dependent phosphorylation of NF- $\kappa \mathrm{B}$ after poly $(\mathrm{I}: \mathrm{C})$ or TNF- $\alpha$ stimulation (Supplementary Figures S6 and S7). Furthermore, Rip3-deficient cells produced equivalent levels of TNF- $\alpha$ and IL-6 in WT cells after treatment with poly(I:C) or TNF- $\alpha$ (Supplementary Figures S6 and S7). These findings imply that RIP3 may not directly modulate inflammatory cytokine release induced by dsRNA.

\section{Discussion}

In the present study, we demonstrated that RIP3 has a critical role in inducing necrosis of the RPE and photoreceptors, as well as in sustaining retinal inflammation during dsRNAinduced retinal degeneration.

Our study showed that RPE cells die mainly by necrosis, not by apoptosis, during dsRNA-induced retinal degeneration. In contrast, photoreceptor cell death exhibited both necrotic and apoptotic features. Whereas caspase inhibitors had little protective effect in this model, RIPK inhibitors, or combined caspase and RIPK inhibitors, had significant amelioration of the pathology observed. In other models of RPE degeneration such as mice immunized with carboxyethylpyrrole-adducted mouse serum albumin and $\mathrm{ApoE}^{-/-}$mice fed with cholesterol-enriched diet, the RPE cells exhibit vesiculation and swelling rather than pyknosis, ${ }^{30,31}$ consistent with necrotic cell death. Although the cell death pathways in slowly progressive human AMD have not been fully characterized, histological studies demonstrated that the budding portion of the RPE into the drusen exhibits disintegration and disruption of the plasma membrane. ${ }^{32}$ In addition, RPE cells overlying drusen show necrotic changes such as cellular enlargement and vacuole formation in early AMD patients. ${ }^{33,34}$ These findings suggest that necrotic pathways may be crucial in RPE cell death in AMD. Interestingly, Yang et al. ${ }^{35}$ reported that caspase activation is decreased in RPE cells that express low levels of caspase-8. As catalytic activity of caspase-8 inhibits the formation of the RIP1-RIP3 complex, ${ }^{16}$ the reduced caspase- 8 expression may predispose RPE cells to undergo necrosis.

In AMD, rod photoreceptor cells in the parafovea degenerate first before the foveal cones die. ${ }^{36}$ Shelley et al. ${ }^{37}$ reported that the dying cones in AMD patient eyes showed an axonal enlargement and swelling, consistent with necrosis. In addition, in vivo imaging of the fovea in patients with geographic atrophy exhibited widening and swelling of the foveal structure, ${ }^{38}$ suggesting that necrotic signaling may be involved in photoreceptor cell death in AMD, especially in cone-cell loss. Interestingly, our recent study demonstrated that the secondary cone-cell death after rod degeneration in a 
mouse model of retinitis pigmentosa demonstrated necrotic morphology and was mediated through RIP kinase. ${ }^{21}$ Although the causes and clinical characteristics of AMD and retinitis pigmentosa differ, these findings suggest that the mechanisms underlying the secondary cone necrosis may be shared by these diseases. RIP kinase is activated downstream of the TNF/Fas family of death ligands as well as dsRNA. Our recent genetic study has identified a susceptibility locus for neovascular AMD, which is located $397 \mathrm{bp}$ upstream of the TNF-related apoptosis-inducing ligand receptor $1 .^{39}$ In addition, Li et al. ${ }^{40}$ recently showed that the RIP1-RIP3 complex forms an amyloid structure - a component of drusen seen in AMD patients. These findings suggest the possible involvement of RIP kinase in AMD pathology, and further studies are necessary to clarify the roles of RIP kinase in cell death and inflammation in AMD.

Reduced inflammatory response in Rip3 ${ }^{-1}$ mice has also been demonstrated in models of sepsis, colitis and viral infection; ${ }^{12,18,19}$ however, the precise mechanisms by which RIP3 mediates inflammation remain to be elucidated. Here, we showed that Rip3 deficiency suppressed the DAMP release from necrotic cells and the cytokine production evoked by necrotic byproducts. In contrast, in line with a previous study by Newton et al., ${ }^{29}$ neither the production of TNF- $\alpha$ and IL- 6 nor the NF- $\kappa$ B activation in response to poly (I: C) was altered in primary RPE cells and macrophages of Rip ${ }^{-1}$ mice. Collectively, these findings suggest that RIP3 may not directly modulate cytokine production or inflammatory cell function, but rather suggest that RIP3induced necrosis of the RPE and photoreceptors enhances retinal inflammation. TLR3 has been implicated in various pathological conditions including viral infection, sepsis and retinal degeneration. ${ }^{8,25,41}$ Although previous studies have mainly focused on a direct pro-inflammatory pathway in TLR3 signaling, our data suggest that the RIP3-dependent necrotic pathway is also important in amplifying tissue inflammation and degeneration in these diseases.

Intracellular components such as proteins, nucleotides and organelles can act as DAMPs to stimulate immune response when they are released from dying or dead cells. HMGB1 is one of the most characterized DAMPs released from necrotic cells. ${ }^{42}$ It was shown that HMGB1 mediates a late-phase inflammatory response and death in septic mice. ${ }^{43,44}$ The extracellular release of HMGB1 is substantially increased during retinal degeneration after retinal detachment, ${ }^{45}$ as well as dsRNA-induced retinal injury. Besides HMGB1, Shichita et al. $^{46}$ recently reported that other DAMPs such as extracellular peroxiredoxin family proteins mediate postischemic inflammation in the brain. In other studies, it was shown that damaged mitochondria released from necrotic cells are critical for inflammatory responses to tissue injury. ${ }^{47,48}$ These findings suggest that several DAMPs may contribute to inflammatory amplification in tissue degeneration and that preventing necrosis, which is the source of multiple DAMPs, may be a potential therapy to protect tissues against injury and excessive inflammation.

In conclusion, our data showed that RIP kinase mediates necrosis of the RPE and photoreceptors in dsRNA-induced retinal degeneration. Blockade of the RIP kinase pathway prevents the DAMP release from dying cells and dampens retinal inflammation, suggesting that RIP kinase may be a potential target for retinal degenerative diseases associated with inflammation.

\section{Materials and methods}

Animals. All animal experiments adhered to the statement of the Association for Research in Vision and Ophthalmology, and the protocols were approved by the Animal Care Committee of Massachusetts Eye and Ear Infirmary. Rip3 ${ }^{-1}$ mice were provided by Dr. Vishva M. Dixit (Genentech, San Francisco, CA, USA) and backcrossed to C57BL/6 mice. ${ }^{29}$ Age-matched WT C57BL/6 mice were purchased from the Jackson Laboratories (Bar Harbor, ME, USA). Mice were fed standard laboratory chow and allowed free access to water in an air-conditioned room with a 12-h light/12-h dark cycle.

Subretinal injection. Mice were anesthetized with intraperitoneal injection of $100 \mathrm{mg} / \mathrm{kg}$ ketamine and $10 \mathrm{mg} / \mathrm{kg}$ xylazine. Pupils were dilated and a sclerotomy was created $\sim 1 \mathrm{~mm}$ posterior to the limbus in the nasal hemisphere with a 30-gauge needle. A Glaser subretinal injector (20-gauge shaft with a 32-gauge tip; BD Biosciences, San Diego, CA, USA) connected to a syringe filled with poly (I: C) solution (1 mg/ml in PBS; Enzo, Farmingdale, NY, USA) was introduced into the subretinal space, and $2 \mu$ l of solution was injected. Successful administration was confirmed by the creation of retinal detachment of approximately one-half of the retina. As a control, PBS was injected using the same procedure. For treatment with inhibitors or antagonists, poly(I:C) solution was mixed with Z-VAD (Enzo), Nec-1 (Sigma, Saint Louis, MI, USA) or Box A (HMGBiotech, Milano, Italy) with the final concentration of $300 \mu \mathrm{M}, 400 \mu \mathrm{M}$ and $10 \mu \mathrm{g} / \mathrm{ml}$, respectively. The doses of the compounds and recombinants were selected based on previous reports. ${ }^{20,49}$ Eyes that sustained marked surgical trauma (for example, retinal or subretinal hemorrhage, bacterial infection) were excluded from further analyses.

Cell culture. RPE cells were prepared as previously described with minor modifications. ${ }^{50}$ The RPE-choroid-sclera complex of C57BL/6 or age-matched Rip $^{-1-}$ mice was separated and incubated in $0.2 \%$ Trypsin (Life Technologies, Grand Island, NY, USA) for $1 \mathrm{~h}$ at $37^{\circ} \mathrm{C}$ in a $5 \% \mathrm{CO}_{2}$ atmosphere. The eyecups were transferred to DMEM medium (Life Technologies), and RPE sheets were scraped off with a forcep. The RPE sheets were triturated to form a single-cell suspension, resuspended in DMEM medium containing 10\% FBS (Life Technologies) and seeded into 35-mm dishes. The RPE cells between passages 3 and 6 were plated into $96-$ or 12 wells at $2 \times 10^{4} \mathrm{cells} / \mathrm{cm}^{2}$ and were used for experiments.

Peritoneal macrophages were obtained from C57BL/6 or age-matched Rip3 ${ }^{-1-}$ mice 3 days after an intraperitoneal injection of $3 \mathrm{ml} 4 \%$ thioglycollate (BD Biosciences) as previously described. ${ }^{51}$ The cells collected from the peritoneal cavity were resuspended in RPMI medium (Life Technologies) containing $10 \% \mathrm{FBS}$, and seeded into 12 wells at $1 \times 10^{5} \mathrm{cells} / \mathrm{cm}^{2}$. Plates were washed twice, $6 \mathrm{~h}$ after seeding, and the adherent macrophages were used directly for the experiments.

Viability assay. Twenty-four hours after poly(l:C) $(5 \mu \mathrm{g} / \mathrm{ml})$ or TNF- $\alpha$ $(30 \mathrm{ng} / \mathrm{ml}$; R\&D Systems, Minneapolis, MN, USA) stimulation, the cell viability was assessed using a modified MTT assay (Cell Counting Kit-8; Dojindo Laboratories, Kumamoto, Japan). Treatment with Z-VAD $(30 \mu \mathrm{M})$ or Nec-1 $(30 \mu \mathrm{M})$ was performed $1 \mathrm{~h}$ before poly $(\mathrm{I}: \mathrm{C})$ or TNF- $\alpha$ stimulation. This assay is based on the cleavage of 2-(2-methoxy-4-nitrophenyl)-3-(4-nitrophenyl)-5(2,4-disulfophenyl)-2H-tetrazolium, monosodium salt (WST-8) to formazan dye by the mitochondrial dehydrogenase enzyme. After incubation with WST-8 for $2 \mathrm{~h}$ at $37^{\circ} \mathrm{C}$, the absorbance was measured at $450 \mathrm{~nm}$ using a microplate leader.

Stimulation of macrophages with the supernatants from RPE cells. WT or Rip3 ${ }^{-1-}$ RPE cells were treated with PBS, poly $(\mathrm{l}: \mathrm{C})(5 \mu \mathrm{g} / \mathrm{ml})$ or poly $(\mathrm{l}: \mathrm{C})$ plus Z-VAD $(30 \mu \mathrm{M})$. Three hours after stimulation, the culture medium was washed three times to remove poly $(\mathrm{I}: \mathrm{C})$ and replaced by fresh medium. After incubation for $24 \mathrm{~h}$, the cellular supernatants were added to untreated WT macrophages. The amount of pro-inflammatory cytokines in the macrophage culture medium was measured using ELISA $24 \mathrm{~h}$ after treatment with the RPE supernatants.

RNA Extraction, RT-PCR and Quantitative Real-Time PCR. The posterior eyecups of mice containing the neuroretina, RPE/choroid and sclera 
were minced with scissors in lysis buffer (QIAGEN, Valencia, CA, USA). Total RNA extraction and reverse transcription were performed as previously reported. ${ }^{20}$ A real-time PCR assay was performed with Prism 7700 Sequence Detection System (Applied Biosystems, Foster City, CA, USA). TaqMan Gene Expression assays were used to check the expression of RIP3 (Mm00444947_m1). For relative comparison of each gene, we analyzed the $C$ t value of real-time PCR data with the $\Delta \Delta C$ t method normalizing by an endogenous control ( $\beta$-actin; Mm00607939_s1).

Western Blotting. The posterior eyecups of mice or cells were collected and lysed in lysis buffer (50 mM Tris- $\mathrm{HCl}(\mathrm{pH}), 120 \mathrm{mM} \mathrm{NaCl}$ and $1 \% \mathrm{NP}-40$, supplemented with a mixture of protein inhibitors (Roche Diagnostics, Basel, Switzerland)). Samples were run on 4-12\% SDS-polyacrylamide gel electrophoresis and transferred onto PVDF membrane. After blocking with blocking buffer (Thermo Scientific, Rockford, IL, USA), the membrane was reacted with RIP3 $(1: 10000$; Sigma $)$ or $p-N F-\kappa B(1: 1000$; Cell Signaling, Danvers, MA, USA) antibody. Membranes were then developed with enhanced chemiluminescence. Lane-loading differences were normalized by $\beta$-actin (1:1000; Cell Signaling).

Histological Examination. Mouse eyes were enucleated and frozen in OCT compound (Sakura Finetechnical Co., Tokyo, Japan). Sections (1- $\mu \mathrm{m}$ thick) were prepared along the horizontal meridian and subsequently stained with hematoxylin and eosin. Five sections were randomly selected from each eye. The mid-peripheral retina in the poly $(1: C)$-injected area $(800 \mu \mathrm{m}$ from the optic nerve in the nasal hemisphere) was photographed, and the ONL thickness was measured at 10 points in each section and averaged. The tissue samples were assigned numbers and letters, and the observers were masked from the conditions.

TUNEL Staining. TUNEL procedure and quantification of TUNEL-positive cells were performed using an ApopTag Fluorescein Direct In Situ Apoptosis Detection Kit (Millipore, Billerica, MA, USA) according to the instructions of the manufacturer. Five sections were randomly selected in each eye. The mid-peripheral retina in poly $(\mathrm{I}: \mathrm{C})$-injected areas $(800 \mu \mathrm{m}$ from the optic nerve in the nasal hemisphere) was photographed, and the number of TUNEL-positive cells in the ONL was counted by masked observers. The retinal area was measured by ImageJ 1.43u software (NIH, Bethesda, MD, USA; http://rsbweb.nih.gov). The data are expressed as TUNEL-positive cells $/ \mathrm{mm}^{2}$ of retinal area.

Flatmount staining. Eyes were enucleated and fixed in 4\% PFA for $1 \mathrm{~h}$. After washing with PBS, the anterior segment and the neuroretina were removed under a microscope. The RPE-choroid-sclera complex was blocked with $10 \%$ non-fat dried milk and $0.3 \%$ triton $\mathrm{X}$ in PBS for $1 \mathrm{~h}$ and was incubated with Alexa Fluor 594-conjugated Zo-1 antibody (1:100; Life Technologies) at $4{ }^{\circ} \mathrm{C}$ overnight. Five areas in poly $(1: C)$-injected areas were randomly photographed at $\times 40$ magnification with a Leica SP2 confocal microscopy, and the number of RPE cells were counted using ImageJ 1.43u software and averaged.

Immunofluorescence. Cryosections were incubated with anti-CD11b antibody (1:100; BD Biosciences) or anti-cleaved caspase-3 (1:100; Cell Signaling) at $4{ }^{\circ} \mathrm{C}$ overnight. A nonimmune serum was used as a negative control. Alexa Fluor 594-conjugated antibodies (1:300; Life Technologies) were used as secondary antibodies. Immunofluorescence images were acquired with a Leica SP2 confocal microscope.

ELISA. The protein levels of TNF- $\alpha$ and IL- 6 in the extracts from posterior eyecups were determined with ELISA kits for TNF- $\alpha$ (R\&D Systems) and IL-6 (R\&D Systems). For HMGB1 measurement, the mouse posterior eyecups were put into $100 \mu \mathrm{l}$ PBS in a 96-well plate and then the vitreous humor was collected. Samples were centrifuged at 15000 r.p.m. for $5 \mathrm{~min}$, and the supernatants were subjected to HMGB1 ELISA (Shinotest Corporation, Tokyo, Japan) according to the manufacturer's instructions.

TEM. The eyes were enucleated, and the posterior segments were fixed in $2.5 \%$ glutaraldehyde and $2 \%$ paraformaldehyde in $0.1 \mathrm{M}$ cacodylate buffer with $0.08 \mathrm{M}$ $\mathrm{CaCl}_{2}$ at $4{ }^{\circ} \mathrm{C}$. The sections of posterior eyecups were postfixed for $1.5 \mathrm{~h}$ in $2 \%$ aqueous $\mathrm{OsO}_{4}$, dehydrated in ethanol and water, and embedded in EPON. Ultrathin sections were cut from blocks and stained with saturated aqueous uranyl acetate and Sato's lead stain. The specimens were observed with Philips CM10 electron microscope (Boston, MA, USA).
Statistical analysis. Statistical differences between two groups were analyzed using the Mann-Whitney U-test. Multiple group comparison was performed by ANOVA followed by Tukey-Kramer adjustments. Differences were considered significant at $P<0.05$.

\section{Conflict of Interest}

The authors declare no conflict of interest.

Acknowledgements. We thank N Michaud (MEEI) and F Morikawa (Kyushu U) for technical assistance, and W Chao (MEEI) for her support in critical review. This work was supported by Research to Prevent Blindness Physician Scientist Award (DGV), NIH NEI R21EY023079-01A1 (DGV) Foundation Lions Eye Research Fund (DGV), Onassis Foundation (DGV), The Yeatts Family Foundation (JWM , DGV), Rena Family Foundation (JWM, DGV), Bausch \& Lomb Vitreoretinal Fellowship (HM, Y Morizane and KM), NEI grant EY014104 (MEEI Core Grant), NIH R01EY022084-01/S1 (KMC) and the Japanese Ministry of Education, Culture, Sports, Science, and Technology grant 25861637 (Y. Murakami).

1. Congdon N, O'Colmain B, Klaver CC, Klein R, Munoz B, Friedman DS et al. Causes and prevalence of visual impairment among adults in the United States. Arch Ophthalmol 2004; 122: $477-485$.

2. Jager RD, Mieler WF, Miller JW. Age-related macular degeneration. N Engl J Med 2008; 358: 2606-2617.

3. Cherepanoff S, McMenamin P, Gillies MC, Kettle E, Sarks SH. Bruch's membrane and choroidal macrophages in early and advanced age-related macular degeneration. Br J Ophthalmol 2010; 94: 918-925.

4. Curcio CA, Johnson M, Huang JD, Rudolf M. Aging, age-related macular degeneration, and the response-to-retention of apolipoprotein B-containing lipoproteins. Prog Retin Eye Res 2009; 28: 393-422.

5. Kaneko H, Dridi S, Tarallo V, Gelfand BD, Fowler BJ, Cho WG et al. DICER1 deficit induces Alu RNA toxicity in age-related macular degeneration. Nature 2011; 471: 325-330.

6. Haines JL, Hauser MA, Schmidt S, Scott WK, Olson LM, Gallins P et al. Complement factor $\mathrm{H}$ variant increases the risk of age-related macular degeneration. Science 2005; 308: 419-421.

7. Zitvogel L, Kepp O, Kroemer G. Decoding cell death signals in inflammation and immunity. Cell 2010; 140: 798-804

8. Cavassani KA, Ishii M, Wen H, Schaller MA, Lincoln PM, Lukacs NW et al. TLR3 is an endogenous sensor of tissue necrosis during acute inflammatory events. J Exp Med 2008 205: 2609-2621.

9. Xu J, Zhang X, Pelayo R, Monestier M, Ammollo CT, Semeraro $\mathrm{F}$ et al. Extracellular histones are major mediators of death in sepsis. Nat Med 2009; 15: 1318-1321.

10. Holler N, Zaru R, Micheau O, Thome M, Attinger A, Valitutti S et al. Fas triggers an alternative, caspase-8-independent cell death pathway using the kinase RIP as effector molecule. Nat Immunol 2000; 1: 489-495.

11. Vandenabeele P, Galluzzi L, Vanden Berghe T, Kroemer G. Molecular mechanisms of necroptosis: an ordered cellular explosion. Nat Rev Mol Cell Biol 2010; 11: 700-714.

12. Cho YS, Challa S, Moquin D, Genga R, Ray TD, Guildford M et al. Phosphorylation-driven assembly of the RIP1-RIP3 complex regulates programmed necrosis and virus-induced inflammation. Cell 2009; 137: 1112-1123.

13. He S, Wang L, Miao L, Wang T, Du F, Zhao L et al. Receptor interacting protein kinase-3 determines cellular necrotic response to TNF-alpha. Cell 2009; 137: 1100-1111.

14. Zhang DW, Shao J, Lin J, Zhang N, Lu BJ, Lin SC et al. RIP3, an energy metabolism regulator that switches TNF-induced cell death from apoptosis to necrosis. Science 2009 325: 332-336.

15. Kaiser WJ, Upton JW, Long AB, Livingston-Rosanoff D, Daley-Bauer LP, Hakem R et al. RIP3 mediates the embryonic lethality of caspase-8-deficient mice. Nature 2011; 471 368-372.

16. Oberst A, Dillon CP, Weinlich R, McCormick LL, Fitzgerald P, Pop C et al. Catalytic activity of the caspase-8-FLIP(L) complex inhibits RIPK3-dependent necrosis. Nature 2011; 471: 363-367.

17. Upton JW, Kaiser WJ, Mocarski ES. Virus inhibition of RIP3-dependent necrosis. Cell Host Microbe 2010; 7: 302-313.

18. Welz PS, Wullaert A, Vlantis K, Kondylis V, Fernandez-Majada V, Ermolaeva M et al. FADD prevents RIP3-mediated epithelial cell necrosis and chronic intestinal inflammation. Nature 2011; 477: 330-334.

19. Duprez L, Takahashi N, Van Hauwermeiren F, Vandendriessche B, Goossens V, Vanden Berghe $\mathrm{T}$ et al. RIP kinase-dependent necrosis drives lethal systemic inflammatory response syndrome. Immunity 2011; 35: 908-918.

20. Trichonas G, Murakami Y, Thanos A, Morizane Y, Kayama M, Debouck CM et al. Receptor interacting protein kinases mediate retinal detachment-induced photoreceptor necrosis and compensate for inhibition of apoptosis. Proc Natl Acad Sci USA 2010; 107: 21695-21700. 
21. Murakami $\mathrm{Y}$, Matsumoto $\mathrm{H}$, Roh $\mathrm{M}$, Suzuki J, Hisatomi $\mathrm{T}$, Ikeda $\mathrm{Y}$ et al. Receptor interacting protein kinase mediates necrotic cone but not rod cell death in a mouse model of inherited degeneration. Proc Natl Acad Sci USA 2012; 109: 14598-14603.

22. Cusson-Hermance N, Khurana S, Lee TH, Fitzgerald KA, Kelliher MA. Rip1 mediates the Trif-dependent toll-like receptor 3- and 4-induced NF-\{kappa\}B activation but does not contribute to interferon regulatory factor 3 activation. J Biol Chem 2005; 280 : 36560-36566.

23. Feoktistova M, Geserick P, Kellert B, Dimitrova DP, Langlais C, Hupe M et al. clAPs block Ripoptosome formation, a RIP1/caspase-8 containing intracellular cell death complex differentially regulated by cFLIP isoforms. Mol Cell 2011; 43: 449-463.

24. Yang Z, Stratton C, Francis PJ, Kleinman ME, Tan PL, Gibbs D et al. Toll-like receptor 3 and geographic atrophy in age-related macular degeneration. N Engl J Med 2008; 359: 1456-1463.

25. Shiose S, Chen Y, Okano K, Roy S, Kohno H, Tang J et al. Toll-like receptor 3 is required for development of retinopathy caused by impaired all-trans-retinal clearance in mice. J Biol Chem 2011; 286: 15543-15555.

26. Gunther C, Martini E, Wittkopf N, Amann K, Weigmann B, Neumann H et al. Caspase-8 regulates TNF-alpha-induced epithelial necroptosis and terminal ileitis. Nature 2011; 477 : 335-339.

27. Lotze MT, Tracey KJ. High-mobility group box 1 protein (HMGB1): nuclear weapon in the immune arsenal. Nat Rev Immunol 2005; 5: 331-342.

28. He S, Liang $Y$, Shao $F$, Wang $X$. Toll-like receptors activate programmed necrosis in macrophages through a receptor-interacting kinase-3-mediated pathway. Proc Natl Acad Sci USA 2011; 108: 20054-20059.

29. Newton K, Sun X, Dixit VM. Kinase RIP3 is dispensable for normal NF-kappa Bs, signaling by the B-cell and T-cell receptors, tumor necrosis factor receptor 1 , and Toll-like receptors 2 and 4. Mol Cell Biol 2004; 24: 1464-1469.

30. Hollyfield JG, Bonilha VL, Rayborn ME, Yang X, Shadrach KG, Lu L et al. Oxidative damage-induced inflammation initiates age-related macular degeneration. Nat Med 2008; 14: 194-198.

31. Malek G, Johnson LV, Mace BE, Saloupis P, Schmechel DE, Rickman DW et al. Apolipoprotein $E$ allele-dependent pathogenesis: a model for age-related retinal degeneration. Proc Natl Acad Sci USA 2005; 102: 11900-11905.

32. Ishibashi T, Patterson R, Ohnishi $\mathrm{Y}$, Inomata $\mathrm{H}$, Ryan SJ. Formation of drusen in the human eye. Am J Ophthalmol 1986; 101: 342-353.

33. Sarks JP, Sarks SH, Killingsworth MC. Evolution of geographic atrophy of the retinal pigment epithelium. Eye (Lond) 1988; 2(Pt 5): 552-577.

34. Curcio CA, Millican CL. Basal linear deposit and large drusen are specific for early age-related maculopathy. Arch Ophthalmol 1999; 117: 329-339.

35. Yang P, Peairs JJ, Tano R, Zhang N, Tyrell J, Jaffe GJ. Caspase-8-mediated apoptosis in human RPE cells. Invest Ophthalmol Vis Sci 2007; 48: 3341-3349.
36. Curcio CA, Medeiros NE, Millican CL. Photoreceptor loss in age-related macular degeneration. Invest Ophthalmol Vis Sci 1996; 37: 1236-1249.

37. Shelley EJ, Madigan MC, Natoli R, Penfold PL, Provis JM. Cone degeneration in aging and age-related macular degeneration. Arch Ophthalmol 2009; 127: 483-492.

38. Schmitz-Valckenberg S, Fleckenstein M, Helb HM, Charbel Issa P, Scholl HP, Holz FG. In vivo imaging of foveal sparing in geographic atrophy secondary to age-related macular degeneration. Invest Ophthalmol Vis Sci 2009; 50: 3915-3921.

39. Arakawa S, Takahashi A, Ashikawa K, Hosono N, Aoi T, Yasuda M et al. Genome-wide association study identifies two susceptibility loci for exudative age-related macular degeneration in the Japanese population. Nat Genet 2011; 43: 1001-1004.

40. Li J, McQuade T, Siemer AB, Napetschnig J, Moriwaki K, Hsiao YS et al. The RIP1/RIP3 necrosome forms a functional amyloid signaling complex required for programmed necrosis. Cell 2012; 150: 339-350.

41. Kawai T, Akira S. Toll-like receptors and their crosstalk with other innate receptors in infection and immunity. Immunity 2011; 34: 637-650.

42. Scaffidi P, Misteli T, Bianchi ME. Release of chromatin protein HMGB1 by necrotic cells triggers inflammation. Nature 2002; 418: 191-195.

43. Wang $\mathrm{H}$, Bloom $\mathrm{O}$, Zhang $\mathrm{M}$, Vishnubhakat JM, Ombrellino M, Che $\mathrm{J}$ et al. HMG-1 as a late mediator of endotoxin lethality in mice. Science 1999; 285: 248-251.

44. Yang $\mathrm{H}$, Ochani $\mathrm{M}$, Li J, Qiang X, Tanovic M, Harris HE et al. Reversing established sepsis with antagonists of endogenous high-mobility group box 1. Proc Natl Acad Sci USA 2004; 101: $296-301$.

45. Arimura N, Ki-i Y, Hashiguchi T, Kawahara K, Biswas KK, Nakamura M et al. Intraocular expression and release of high-mobility group box 1 protein in retinal detachment. Lab Invest 2009; 89: 278-289.

46. Shichita T, Hasegawa E, Kimura A, Morita R, Sakaguchi R, Takada I et al. Peroxiredoxin family proteins are key initiators of post-ischemic inflammation in the brain. Nat Med 2012; 18: 911-917.

47. Zhou R, Yazdi AS, Menu P, Tschopp J. A role for mitochondria in NLRP3 inflammasome activation. Nature 2011; 469: 221-225.

48. Iyer SS, Pulskens WP, Sadler JJ, Butter LM, Teske GJ, Ulland TK et al. Necrotic cells trigger a sterile inflammatory response through the Nlrp3 inflammasome. Proc Natl Acad Sci USA 2009; 106: 20388-20393.

49. Yang H, Rivera Z, Jube S, Nasu M, Bertino P, Goparaju C et al. Programmed necrosis induced by asbestos in human mesothelial cells causes high-mobility group box 1 protein release and resultant inflammation. Proc Natl Acad Sci USA 2010; 107: 12611-12616.

50. Sugita S, Streilein JW. Iris pigment epithelium expressing CD86 (B7-2) directly suppresses $\mathrm{T}$ cell activation in vitro via binding to cytotoxic $T$ lymphocyte-associated antigen 4 . J Exp Med 2003; 198: 161-171.

51. Nakazawa T, Hisatomi T, Nakazawa C, Noda K, Maruyama K, She H et al. Monocyte chemoattractant protein 1 mediates retinal detachment-induced photoreceptor apoptosis. Proc Natl Acad Sci USA 2007; 104: 2425-2430.

\section{Supplementary Information accompanies this paper on Cell Death and Differentiation website (http://www.nature.com/cdd)}

